carried on in 1943. The second of these was originally concerned with Northern Rhodesia and Jamaica, but has now been extended to Nyasaland in view of the valuable data on that Colony which became available during the year. With regard to the third, a paper on the expenditure of county boroughs in England is now in the press and the full inquiry will be published under the title "Wealth and Poverty in Local Government", as there are insufficient data to permit a calculation of the local tax burden comparable with that made for the national tax survey in "The Burden of British Taxation". Of the inquiries upon which work only started in 1942 , that into profit margins is the most significant. Other plans which came into operation during the year were Dr. R. R. Kuczynski's study of post-war population problems, and studies in aspects of commercial policy, directed by Dr. P. Barrett Whale. Two continuous projects were initiated in 1942 : the observational study of the effects of the War on the credit policy and credit mechanisms of the City of London and the "Weekly Diary: Summary of Economic and Social Changes". It is intended to continue the former for the duration of the War, and a full-length descriptive and analytical summary is expected to result.

\section{Vital Statistics of Canada}

ACCORDING to the twentieth annual report on vital statistics for 1940 and the preliminary annual report for 1941 , both recently issued by the Canadian Bureau of Statistics, the population of the Dominion has increased in the last twenty years from 8,776,000 in 1921 to $11,443,000$ in 1941. The largest populations were found in Quebec $(3,329,000)$ and Ontario $(3,765,000)$. Although the birth-rate for $1941(22 \cdot 3$ per 1,000 population) showed a slight increase, the rate has fallen from an average of $24 \cdot 1$ in the quinquennium $1926-30$ to $21 \cdot 5$ in 1940 . The rate was highest in New Brunswick $(25 \cdot 9)$ and lowest in British Columbia $(17 \cdot 4)$. The stillbirth-rate in 1941 was $2 \cdot 6$ per cent of all births. As regards infant mortality the provisional figure for 1941 was 60 per 1,000 live births and the rate of 56 for 1940 was the lowest recorded. The maternal mortality-rate for 1940 was $4 \cdot 0$ per 1,000 births and that for 1941 was $3 \cdot 5$. The marriage-rate showed a progressive increase from $7 \cdot 3$ per 1,000 population in the period $1926-30$ to 10.8 in 1940 and 10.7 in 1941. The general deathrate was $9 \cdot 6$ per 1,000 , the lowest rate being found in Saskatchewan and in Alberta.

\section{Sources of Engineering Information}

THE fifth number of the A S L I B War-time Guides to British Sources of Specialised Information (March 1943) deals with engineering other than electrical. These are listed under Government departments; professional, research and trade organizations; and educational organizations and technical educational organizations. The list of Government departments is not comprehensive, but is confined to sources of information still usually accessible. All references to industrial firms have been omitted. Electrical engineering and telecom. munications are covered by Guide No. 3. An additional section lists a number of organizations dealing with fuel, raw materials, transport, etc., which while not directly related to engineering are concerned with materials and aspects of work of immediate interest to engineers. The section devoted to periodicals lists separately those printing abstracts or lists of references; periodicals issued by professional and industrial organizations; other trade and technical periodicals; selected periodicals relating to auxiliary interests; engineering annuals; and annuals dealing with auxiliary interests.

\section{Recent Earthquakes}

The U.S. Coast and Geodetic Survey, in co-operation with Science Service and the Jesuit Seismological Association, has determined the epicentres of two recent earthquakes. The first of these was on June 8 at about $20 \mathrm{~h} \cdot 42 \cdot 2 \mathrm{~m}$. U.T. and occurred near latitude $19^{\circ} \mathrm{N}$., longitude $116^{\circ} \mathrm{E}$. This is in the South China Sea, west of Luzon in the Philippine Islands. The second was on June 9 at about $3 \mathrm{~h} .6 \cdot 7 \mathrm{~m}$. U.r. and had its epicentre near latitude $9^{\circ} \mathrm{N}$., longitude $120^{\circ} \mathrm{E}$., which is in the Sulu Sea north-east of Borneo. On the morning of Friday, July 16, a strong earthquake was felt throughout the Island of Jamaica. The epicentre was some ninety miles from Kingston in the Balaclava district, where some damage was done to property though there are no reports of any loss of life.

\section{Announcements}

THE Association of Scientific Workers (West Midland Area) has arranged an open conference on "Science under Fascism and Democracy", to be held at the Town Hall, Birmingham, on August 22 at 3 p.m. The Lord Mayor of Birmingham (Councillor W. S. Lewis) will open the conference, and the chair will be taken by Prof. M. L. E. Oliphant. Among the speakers who will deal with the sharp contrast in the approach to science and its applications, and also the treatment of scientific workers, in Democratic and Fascist countries, are Prof. J. B. S. Haldane (Great Britain), Dr. J. H. Hildebrand (United States), P. H. Yap (China), M. Fournier (France), Dr. A. van Anrooy (Holland), Dr. B. Schober (Czechoslovakia), Dr. A. Fischer (Austria), and Dr. J. G. Siebert (Germany). In the evening following the conference, films will be shown depicting scientific activities in many countries.

The fifth supplement to the "British Pharmaccutical Codex" contains new monographs describing the insecticides derris and lonchocarpus, and new regulations which are introduced because of the shortage of rubber and quinine. Where the "Codex" insists on rubber, the supplement allows other materials to be used, and where the "Codex" includes quinine the supplement omits it except in the cases where it is considered essential. This supplement also includes a cumulative index to all the five supplements which have been issued.

The New York Academy of Medicine, in co-opera. tion with the State Department of Health, the City Department of Health and six of the leading voluntary organizations of maternal welfare and child health, recently celebrated the hundredth anniversary of the publication by Oliver Wendell Holmes of the paper entitled "The Contagiousness of Puerperal Fever".

Erratum. In the letter entitled "Production of Ion Clusters by X-Rays" (Nature, June 19), sixth line from bottom of first column, p. 698, for " $B_{Z}=11 \cdot 2$ ev." read " $B_{Z}=11 \cdot 2 Z$ ev.". 